\title{
ADHD and Childhood Epilepsy: An Egyptian Comparative Study
}

\author{
Maha A. Hassan*, Rasha N. Saleh**, Enas M. Hasan**, \\ Nermin Aly Hamdy** and Salwa Mohamed Rabie* \\ * Department of Psychiatry, Minia University, Egypt \\ ** Department of Neurology, Minia University, Egypt
}

\begin{abstract}
Background: Attention Deficit Hyperactivity Disorder (ADHD) and epilepsy are both common childhood disorders and both can have significant negative consequences on a child's behavioral, learning, and social development. Objectives: To estimate the prevalence of ADHD in children with epilepsy, prevalence of electroencephalographic (EEG) abnormalities in ADHD children, and to study the relation between ADHD and epilepsy. Subjects and Methods: This study included 71 patients; 40 patients diagnosed clinically as ADHD according to DSM-V. and 31 patients with epilepsy during the period of 6 months from 1 Jan. 2019 to 30 June 2019. The age of both groups of patients ranged between 4-16 years old. All patients were subjected to detailed history taking, thorough general and neurological examination, EEG study and assessment of ADHD symptoms using Conners' Parent Rating Scales-Revised: Long (CPRS-R:L). Children with apparent intellectual disabilities were excluded. Results: Eighteen patients (58.1\%) of the epilepsy group were diagnosed as having ADHD according to CPRS-R:L, while EEG showed epileptiform changes in 13 patients (32.5\%) of the ADHD group. There were highly significant difference between ADHD and Epilepsy group regarding (CPRS-R:L) subscales as inattention, impulsivity, hyperactivity cognitions and Emotional lability. However, There were no correlations between the age of patients in ADHD group and subscales of CPRS-R:L except in cognition and inattention subscales ( $\mathrm{p}=0.023 \& 0.048$ respectively). There were significant correlation between emotional-lability and inattention subscales of CPRS-R:L in ADHD group and gender of the patients. Emotional lability and inattention were significantly more among males in ADHD group. There were no significant difference in EEG changes or their laterality and degree of CPRS-R:L either total scores or its subscales for both groups. Conclusions: ADHD was diagnosed in epileptic children and EEG changes were prevalent in ADHD children, highly significant difference between ADHD and epilepsy group regarding CPRS-R:L subscales as inattention, impulsivity, hyperactivity, cognition and lability.

Keywords: ADHD, epilepsy, EEG, Egyptian.
\end{abstract}

\section{Introduction}

ADHD and epilepsy both are common childhood disorders and both can have significant negative consequences on a child's behavioural, learning, and social development ${ }^{1}$.

Epilepsy, defined as two or more unprovoked seizures, affects up to $1 \%$ of children and adolescents ${ }^{2}$ while the incidence of childhood ADHD is between 5-16\% $\%^{3,4}$.
The relationship between epilepsy and ADHD is complex and poorly understood $^{1,5}$. The prevalence of symptoms consistent with attention deficit/ hyperactivity disorder (ADHD) in children with epilepsy has been observed to be in the range of 12 to $39 \%$ in epidemiological studies. Thus, the prevalence of ADHD is higher in children with epilepsy than that would be expected in the general population $^{6}$. 
Children with comorbid epilepsy and ADHD appear to differ from community samples of children with ADHD in that they are more likely to have ADHD Predominantly Inattentive Type and are more likely to have an equal ratio of males to females ${ }^{7}$.

Bennet-Back and colleagues (2011) suggested that the relationship between ADHD and epilepsy is not random, and instead may reflect a common underlying causative etiology. The possible mechanisms they outline include hereditary factors with a common propensity to both conditions that may alter the levels of various brain neurotransmitters or may affect brain plasticity, neurogenesis, and apoptosis. $^{8}$

The present study aims to estimate the prevalence of attention deficit hyperactivity disorder (ADHD) in children with epilepsy and whether they are different from children with pure ADHD, and prevalence of EEG abnormalities among ADHD children. It also aims to compare both groups regarding clinical and other variables.

\section{Methods}

This study was a cross sectional study carried upon 71 patients who attended 'Neurology and Psychiatry Outpatients Clinic', Minia University Hospital, Minia governorate during the period from $1^{\text {st }}$ of January to $30^{\text {th }}$ of June 2019. The first group of patients included 40 patients diagnosed as ADHD according to DSM-IV. The second group included 31 patients diagnosed clinically as epilepsy. The age of both group of patients ranged between 4-16 years old.

We excluded children with apparent intellectual disabilities (IQ less than 75), children with neurological illness other than epilepsy and ADHD patients with established diagnosis of epilepsy.

Verbal consents were taken from all caregivers of the studied children. This was approved by local ethics committee.
All patients were subjected to detailed history taking, thorough general and neurological examination. Electroencephalography (EEG) study was done using 16- channel Digital EEG (Nihon Kohden machine, Model JE-921A, Nihon Kohden Corporation, Japan).

Assessing of ADHD symptoms was done using Conners' Parent Rating ScalesRevised: Long (CPRS-R:L). It is an assessment for children aged 3 through 17 years designed to measure cognitive, behavioral, and emotional problems from teacher and parent perspectives. The long version of the CRS-R is based on the DSM-IV symptoms linked to ADHD and comorbid disorders. The CRS-R Parent Rating Scales-Revised (CPRS-R) long version includes 80 items in the following subscales; oppositional, social problems, cognitive problems, inattention, psycho-somatic, hyperactivity, anxious-shy, perfectionism, lability and impulsivity. Items are related to internalizing and externalizing behaviors representing problem behaviors. Test scores were interpreted as follows; 0-55 was considered as normal, 56-60 slight ADHD, 61-65 mild ADHD and 66-90 significant ADHD ${ }^{9}$.

\section{Statistical Analysis}

The data were coded and verified prior to data entry. The Statistical Package for the Social Sciences (SPSS Inc., Chicago. USA) version 19.0 for windows was used for data entry and analysis. Descriptive Statistics were calculated. For qualitative data, Chi square test was used and for quantitative data, student-t test (for two groups) was used. Z-test was used to compare proportions and correlations. A significant $\mathrm{P}$ value was considered when $\mathrm{P}$-value was less than 0.05 .

\section{Results}

The present study included 40 patients with ADHD, 36 males and 4 females, mean age \pm SD was $6.88 \pm 2.33$ and 31 patients with epilepsy, 17 males and 14 females, mean age $\pm \mathrm{SD}$ was $10.06 \pm 2.92(\mathrm{P}<0.001)$.

Sociodemographic data and important history data of both groups are shown in 
Table (1). On analyzing perinatal and developmental factors and family history, the epilepsy group had a statistically significant past history of febrile convulsion $(\mathrm{P}=0.03)$ compared to the ADHD group. The epilepsy group also had more family history of epilepsy compared to the ADHD group but not reaching statistical signifycance $(\mathrm{P}=0.06)$. The ADHD group had statistically significant family history of ADHD $(\mathrm{P}=0.05)$. Regarding comorbid psychiatric disorders with ADHD and Epilepsy. no statistically significant differrences were found.

Table (1): Sociodemographic data of the studied groups of patients

\begin{tabular}{|l|c|c|c|}
\hline & $\begin{array}{c}\text { ADHD } \\
\text { (N=40) }\end{array}$ & $\begin{array}{c}\text { Epilepsy } \\
\text { (N=31) }\end{array}$ & P \\
\hline Male & $\begin{array}{c}\text { (N6) } \\
\text { Female }\end{array}$ & 17 & $0.001^{*}$ \\
\hline Age (mean \pm SD) & $6.88 \pm 2.33$ & $10.06 \pm 2.92$ & $0.000^{* * *}$ \\
\hline $\begin{array}{l}\text { Prenatal history } \\
\text { (mother illness or drug intake) }\end{array}$ & 9 & 5 & 0.7 \\
\hline Postnatal history (low birth weight, & 10 & 3 & 0.3 \\
cyanosis or jaundice) & & & \\
\hline Developmental delay & 5 & 7 & 0.2 \\
\hline Past history of febrile convulsion & 0 & 4 & $0.03^{*}$ \\
\hline Family history of epilepsy & 2 & 3 & 0.06 \\
\hline Family history of ADHD & 8 & 2 & $0.05^{*}$ \\
\hline Consanguinity & 2 & 4 & 0.2 \\
\hline History of: & 7 & & \\
Nocturnal enuresis & 5 & 2 & $\mathrm{P}=0.1$ \\
Delayed language development & 4 & 2 & \\
Conduct disorder & 1 & 2 & \\
Depressive Symptoms & 0 & 1 & \\
Dissociative Symptoms & 1 & 3 & \\
Learning disabilities & 5 & & \\
\hline
\end{tabular}

ADHD: Attention Deficit Hyperactivity Disorder

$P$ value $<0.05=$ significant

Of the epilepsy group, 24 patients $(77 \%)$ had generalized tonic-clonic (GTC) seizures, 2 patients had absence, 3 patients had left focal fits and lastly 2 patients had right focal fits. Fifteen patients were not on antiepileptic drugs (AEDs) at time of presentation, while 16 patients were using antiepileptic drugs. (Valproate, Carbamazepine and Phenytoin).

Among the ADHD Group, EEG was normal in 26 patients, 1 patient had nonspecific changes and 13 patients $(32.5 \%)$ had generalized epileptiform changes (epileptiform changes include sharp waves, spikes, sharp-wave complexes, spike-wave complexes or polyspikes). On the other hand, 8 of the epilepsy group had normal EEG, 3 patients had non-specific changes and 20 patients had epileptiform changes. Regarding laterality. of the 20 patients, 13 patients had bilateral discharges, 4 patients had right sided discharges and 3 patients had left sided discharges. Regarding localization of the epileptic discharge, 11 patients had generalized epileptic discharge, 4 patients had temporal discharge, 4 patients had fronto-temporal discharge and 1 patient had parietal discharge (table 2). 
Table (2): Electroencephalogram study in both groups:

\begin{tabular}{|l|c|c|c|}
\hline & ADHD(N=40) & Epilepsy(N=31) & P \\
\hline Normal & 26 & 8 & $0.004^{*}$ \\
Non specific & 1 & 3 & \\
Epileptiform changes & 13 & 20 & $0.005^{*}$ \\
\hline Side: Bilateral & 13 & 13 & \\
Right sided & 0 & 4 & $0.005^{*}$ \\
Left sided & 0 & 3 & \\
Site: Generalized & 13 & 11 & \\
Temporal & 0 & 4 & \\
Fronto-tempral & 0 & 4 & \\
Parietal & 0 & 1 & \\
\hline
\end{tabular}

ADHD: Attention Deficit Hyperactivity Disorder

In the ADHD group, only one patient diagnosed clinically as ADHD had normal scores in CPRS-R:L, 2 patients (5\%) had slight degree and $37(92.5 \%)$ had significant degree. On the other hand, 18 patients $(58.1 \%)$ of the epilepsy group diagnosed as having ADHD according to CPRS-R: L; 1 patient (3.2\%) had slight degree, $2(6.5 \%)$ had mild and 15 patients (48.4\%) had significant scores and 13 patients $(41.9 \%)$ had within normal scores (table 3).

Table (3): Degrees of ADHD in both groups by Conners' Parent Rating Scales-Revised: Long (CPRS-R:L):

\begin{tabular}{|l|c|c|}
\hline & $\begin{array}{c}\text { ADHD group } \\
\mathbf{N = 4 0}\end{array}$ & $\begin{array}{c}\text { Epilepsy group } \\
\mathbf{N = 3 1}\end{array}$ \\
\hline Normal & $1(2.5 \%)$ & $13(41.9 \%)$ \\
\hline Slight & $2(5 \%)$ & $1(3.2 \%)$ \\
\hline Mild & 0 & $2(6.5 \%)$ \\
\hline Severe & $37(92.5 \%)$ & $15(48.4)$ \\
\hline
\end{tabular}

ADHD: Attention Deficit Hyperactivity Disorder

All CPRS-R:L subscales scores were higher among ADHD group. The differences were significantly higher in all subscales except in opposition and perfectionism subscales (Table 4).

Table (4): Comparison between ADHD and Epilepsy groups regarding Conners' Parent Rating Scales-Revised: Long (CPRS-R:L) subscales

\begin{tabular}{|l|c|c|c|}
\hline & $\begin{array}{c}\text { ADHD } \\
\text { mean } \pm \text { SD }\end{array}$ & $\begin{array}{c}\text { Epilepsy } \\
\text { mean } \pm \text { SD }\end{array}$ & P \\
\hline Opposition & $18.42 \pm 1.13$ & $12.12 \pm 7.31$ & 0.101 \\
\hline Cognition Problems & $20.27 \pm 8.27$ & $10.00 \pm 8.69$ & $0.000^{* * *}$ \\
\hline Hyperactivity & $17.15 \pm 4.74$ & $9.45 \pm 7.31$ & $0.000^{* * *}$ \\
\hline Anxious-Shy & $10.47 \pm 4.79$ & $7.67 \pm 3.90$ & $0.010^{*}$ \\
\hline Perfectionism & $6.65 \pm 4.52$ & $5.83 \pm 5.18$ & 0.484 \\
\hline Social Problems & $6.62 \pm 2.87$ & $3.19 \pm 3.37$ & $0.020^{*}$ \\
\hline Psychosomatic & $6.15 \pm 4.03$ & $3.93 \pm 3.71$ & $0.020^{*}$ \\
\hline Emotional-Lability & $7.50 \pm 3.15$ & $4.29 \pm 3.17$ & $0.000^{* * *}$ \\
\hline Inattention & $14.00 \pm 5.09$ & $8.09 \pm 6.71$ & $0.000^{* * *}$ \\
\hline Impulsivity & $16.75 \pm 5.23$ & $9.29 \pm 6.05$ & $0.000^{* * *}$ \\
\hline
\end{tabular}

ADHD: Attention Deficit Hyperactivity Disorder

$\mathrm{P}$ value $<0.05=*$ Significant 
There were no significant correlations between the age of patients in both group and subscales of CPRS-R:L except in cognition and inattention subscales in the ADHD group (i.e., as the age of the patients increases, there is increase in the inattention and cognition problems). Also, no significant correlation was found between any subscale of CPRS-R:L and age of onset of seizure in the epilepsy group (Table5).

Table (5): The correlations between CPRS-R:L subscales, age of patients with ADHD, age of patients with Epilepsy and age of seizure onset in patients with Epilepsy.

\begin{tabular}{|l|c|c|c|}
\hline & $\begin{array}{c}\text { Age of patients with } \\
\text { ADHD }\end{array}$ & $\begin{array}{c}\text { Age of patients with } \\
\text { Epilepsy }\end{array}$ & $\begin{array}{c}\text { Age of seizure onset } \\
\text { in patients with } \\
\text { Epilepsy }\end{array}$ \\
\hline Opposition & $\mathrm{R}=.268$ & $\mathrm{R}=-.153$ & $\mathrm{R}=-.140$ \\
& $\mathrm{P}=.095$ & $\mathrm{P}=.410$ & $\mathrm{P}=.453$ \\
Cognition & $\mathrm{R}=.358$ & $\mathrm{R}=.008$ & $\mathrm{R}=-.063$ \\
Problems & $\mathrm{P}=.023^{*}$ & $\mathrm{P}=.986$ & $\mathrm{P}=.738$ \\
\hline Hyperactivity & $\mathrm{R}=-.047$ & $\mathrm{R}=-.090$ & $\mathrm{R}=-.140$ \\
& $\mathrm{P}=.774$ & $\mathrm{P}=.629$ & $\mathrm{P}=.453$ \\
\hline Anxious-Shy & $\mathrm{R}=-.010$ & $\mathrm{R}=.037$ & $\mathrm{R}=-.192$ \\
& $\mathrm{P}=.953$ & $\mathrm{P}=.843$ & $\mathrm{P}=.301$ \\
\hline Perfectionism & $\mathrm{R}=.117$ & $\mathrm{R}=.318$ & $\mathrm{R}=.031$ \\
& $\mathrm{P}=.473$ & $\mathrm{P}=.082$ & $\mathrm{P}=.869$ \\
\hline Social Problems & $\mathrm{R}=.281$ & $\mathrm{R}=.090$ & $\mathrm{R}=.060$ \\
& $\mathrm{P}=.079$ & $\mathrm{P}=.630$ & $\mathrm{P}=.747$ \\
\hline Psychosomatic & $\mathrm{R}=.224$ & $\mathrm{R}=.122$ & $\mathrm{R}=.315$ \\
& $\mathrm{P}=.164$ & $\mathrm{P}=.512$ & $\mathrm{P}=.084$ \\
\hline Emotional- & $\mathrm{R}=.258$ & $\mathrm{R}=.041$ & $\mathrm{R}=.002$ \\
Lability & $\mathrm{P}=.109$ & $\mathrm{P}=.826$ & $\mathrm{P}=.992$ \\
\hline Inattention & $\mathrm{R}=.315$ & $\mathrm{R}=.064$ & $\mathrm{R}=-.005$ \\
& $\mathrm{P}=.048^{*}$ & $\mathrm{P}=.731$ & $\mathrm{P}=.980$ \\
\hline Impulsivity & $\mathrm{R}=.213$ & $\mathrm{R}=-.167$ & $\mathrm{R}=-.182$ \\
& $\mathrm{P}=.187$ & $\mathrm{P}=.369$ & $\mathrm{P}=.327$ \\
\hline
\end{tabular}

CPRS-R:L: Conners' Parent Rating Scales-Revised: Long, ADHD: Attention Deficit Hyperactivity Disorder

Grades of r: 0.00 to 0.24 (weak or no association), 0.25 to 0.49 (fair association), 0.50 to 0.74 (moderate association) and $\geq$ 0.75 (strong association). $\mathrm{P}$ value $<0.05=$ significant $=*$ Gender difference in CPRSR: L subscales are shown in table (6) for both groups. There were no significant gender differences in both groups except in emotional-liability and inattention. Emotional lability and inattention were significantly more among males in ADHD group. 
Table (6): Gender difference in CPRS-R: $L$ subscales in both groups

\begin{tabular}{|c|c|c|c|c|c|c|}
\hline & & ADHD & & & Epilepsy & \\
\hline & $\begin{array}{c}\text { Males } \\
(\mathrm{n}=36) \\
\text { Mean } \pm \text { SD }\end{array}$ & $\begin{array}{c}\text { Females } \\
(n=4) \\
\text { Mean } \pm \text { SD }\end{array}$ & $\mathbf{P}$ & $\begin{array}{c}\text { Males } \\
(\mathrm{n}=11) \\
\text { Mean } \pm \text { SD }\end{array}$ & $\begin{array}{c}\text { Females } \\
(n=7) \\
\text { Mean } \pm \text { SD }\end{array}$ & $\mathbf{P}$ \\
\hline Opposition & $18.97 \pm 5.89$ & $13.50 \pm 7.18$ & 0.09 & $13.94 \pm 6.47$ & $9.92 \pm 7.89$ & 0.131 \\
\hline Cognition Problems & $21.02 \pm 8.10$ & $13.50 \pm 7.50$ & 0.08 & $12.41 \pm 8.68$ & $7.07 \pm 8.05$ & 0.089 \\
\hline Hyperactivity & $17.52 \pm 4.69$ & $13.75 \pm 4.27$ & 0.13 & $11.47 \pm 7.62$ & $7.00 \pm 6.32$ & 0.090 \\
\hline Anxious-Shy & $10.86 \pm 4.88$ & $7.00 \pm 1.41$ & 0.13 & $7.00 \pm 4.13$ & $8.50 \pm 3.56$ & 0.294 \\
\hline Perfectionism & $6.63 \pm 4.47$ & $6.75 \pm 5.73$ & 0.96 & $5.35 \pm 5.44$ & $6.42 \pm 4.98$ & 0.574 \\
\hline Social Problems & $6.72 \pm 2.99$ & $5.75 \pm 1.50$ & 0.53 & $3.88 \pm 3.46$ & $2.35 \pm 3.17$ & 0.215 \\
\hline Psychosomatic & $6.33 \pm 4.14$ & $4.50 \pm 2.64$ & 0.39 & $3.52 \pm 4.03$ & $4.42 \pm 3.36$ & 0.512 \\
\hline $\begin{array}{l}\text { Emotional- } \\
\text { Lability }\end{array}$ & $7.83 \pm 3.10$ & $4.50 \pm 1.91$ & $0.04 *$ & $4,47 \pm 3.48$ & $4,07 \pm 2.86$ & 0.734 \\
\hline Inattention & $14.55 \pm 4.87$ & $9.00 \pm 4.89$ & $0.04 *$ & $10.00 \pm 6.80$ & $5.78 \pm 6.06$ & 0.082 \\
\hline Impulsivity & $17.25 \pm 5.01$ & $12.25 \pm 5.73$ & 0.07 & $10.17 \pm 5.87$ & $8.21 \pm 6.30$ & 0.378 \\
\hline
\end{tabular}

Total score and subscales of CPRS-R:L were higher among patients with GTCS and

those with left focal seizures but results were not significant (Table 7).

Table (7): Total CPRS_R:L scores in different types of seizures

$\mathrm{P}=.439$

\begin{tabular}{|l|c|}
\hline & Mean $\mathbf{A D}$ \\
\hline GTCS $\mathbf{n}=\mathbf{2 4}$ & $85.08 \pm 54.54$ \\
\hline Absence $\mathbf{n = 2}$ & $35.50 \pm 34.64$ \\
\hline Left focal $\mathbf{n}=\mathbf{3}$ & $80.33 \pm 14.97$ \\
\hline Right focal $\mathbf{n = 2}$ & $43.00 \pm 14.14$ \\
\hline Total $\mathbf{n}=\mathbf{3 1}$ & $78.70 \pm 50.84$ \\
\hline
\end{tabular}

CPRS-R:L:Conners' Parent Rating Scales-Revised: Long, ADHD: Attention Deficit Hyperactivity Disorder, GTCS: Generalised tonic clonic seizure

There were no significant correlation between EEG changes and degree of CPRS-R:L $(\mathrm{P}=.65)$ or total scores $(\mathrm{p}=0.59)$ for both groups. Also there were no significant correlation between laterality or site of epileptiform discharges and subscales of CPRS-R:L.(P=67). Epileptic patients not on AEDs had significantly higher total scores of CPRS-R:L (mean 101.47) than those on AEDs (mean 57.37) $(\mathrm{p}=0.013)$.

\section{Discussion}

Epilepsy and attention-deficit hyperactivity disorder (ADHD) were reported to co-occur at rates higher than expected for coincidental findings ${ }^{6}$. Many hypotheses have been put forward in an attempt to explain the co-existence of or apparent association between ADHD and epilepsy. Brikell and colleagues., (2018) demon-strated a strong and etiologically complex association between epilepsy and ADHD, with shared familial factors and risk factors unique to the individual contributing to co-occurrence of the disorders. ${ }^{10}$ ADHD and epilepsy may exist within a common syndrome complex both may have a genetic predisposition ${ }^{11}$.

Also, Bennet-Back and colleagues (2011) suggest that this relationship may reflect a common underlying causative etiology. The possible mechanisms they outline include hereditary factors with a common prope- 
nsity to both conditions that may alter the levels of various brain neurotransmitters or may affect brain plasticity, neurogenesis, and apoptosis ${ }^{8}$. Noradrenergic system dysregulation, and psychosocial factors were suggested by Titlic (2009) ${ }^{12}$.

Antiepileptic drugs (AEDs) may contribute to both attentional difficulties and increased levels of activity, including irritability in a number of epileptic children ${ }^{13}$. The observation that behavioral and attentional problems may be seen prior to the onset of epilepsy would suggest that they are unlikely to be the direct effect of clinical seizures or AEDs ${ }^{14}$.

In the present study, 18(58.1\%) epileptic children were diagnosed to have ADHD using CPRS-R:L This is in agreement with Dunn and colleagues. (2003) who reported the prevalence of attention-deficit-hyperactivity disorder (ADHD) associated with childhood epilepsy; to range from 8 to $77 \%$, depending on the sample studied and the criteria used for diagnosis ${ }^{7}$. Other studies found ADHD in 20\%-40\%. of children with epilepsy ${ }^{15}$. Our finding is more than that reported by Duran and colleagues., (2014) who interviewed sixty children with idiopathic epilepsy for ADHD, they found eight patients had ADHD symptoms (13\%). However, the majority of their patients had been diagnosed with epilepsy within the past five years, most of them were seizurefree for more than two years, and almost half of their patients were either without antiepileptic drug treatment or undergoing withdrawal. Therefore, they consider that their results reflect cleaner data with less interference of seizures and drug treatment on the presence of the comorbid condition. ${ }^{16}$ Also, Choudhary and colleagues (2018) reported among 73 children with epilepsy, 23\% ( $\mathrm{n}=17)$ had comorbid ADHD $^{17}$.

In the present study, the scores of epileptic children, were significantly lower than children with ADHD in most of the subscales of CPRS-R:L, except in opposition and perfectionism subscales. This finding disagrees with Dunn and collea- gues. (2003) who reported that the majority of affected children having ADHD combined type, ${ }^{7}$ while Hesdorf (2004) found Inattention to be more common than Hyperactivity and Impulsivity as a form of ADHD symptom in children with epilepsy ${ }^{18}$. Duran and colleagues., (2014) found eight patients (13\%) had ADHD symptoms (13\%), seven had the inattentive ADHD subtype ${ }^{16}$. Choudhary and colleagues (2018) reported that children with epilepsy with comorbid ADHD, 59\% had predominantly inattentive type, $35 \%$ combined type, and $6 \%$ predominantly hyperactive-impulsive ${ }^{17}$.

In present study all subscales of CPRS-R:L were higher among patients with generalized tonic-clonic seizures (GTCS) and those with left focal seizures but results were not significant. This is in agreement with Dunn and colleagues (2003) who found that $36 \%$ children with epilepsy met DSM-IV criteria for ADHD and there was a tendency for ADHD to occur more frequently in those with generalized seizures ${ }^{7}$.

Semrud-Clikeman and Wical, (1999) reported children with complex partial seizures to have significant difficulty with aspects of sustained attention, irrespective of whether there is a preceding or concurrent diagnosis of ADHD. ${ }^{19}$ Impaired attention has also been described in children with benign childhood epilepsy with centro-temporal (Rolandic) spikes. Right sided interictal epileptiform activity in these children interferes with right hemispheric activity including attention ${ }^{20}$, More recent studies found $59.0 \%$ of children with frontal lobe epilepsy suffered from ADHD as well ${ }^{21}$. However, we could not find any significant difference in relation to laterality of EEG abnormality.

Other studies have suggested that the seizure or epilepsy type is not important. Williams and colleagues (1998) found a significant reduction in visual and verbal attention in children with epilepsy that was irrespective of seizure type, suggesting a possible general developmental effect of epilepsy or its treatment, or both ${ }^{22}$. 
We could not find significant correlation between subscales of CPRS-R:L and age of onset of seizures in the epilepsy group, which is in disagreement with Ying and colleagues., (2012) who concluded that the earlier the epilepsy onset, the higher the frequency of the co-morbidity of ADHD occurrence ${ }^{23}$ However, we found significant correlation between age of patient and inattention and cognitive subscales (i.e., The higher the age of patients with ADHD the more the cognitive impairment and inattention), which can be due to the chronic effect of the disorder.

On the other hand, we found that 32.5\% (13 patients) of the ADHD group had epileptiform EEG changes. This is in agreement with other studies where EEG has also been reported to be abnormal in children with ADHD, some showing epilepticform activity. The reported incidence ranges from $6.1 \%$ to $30.1 \%$ of children with ADHD $^{15,24}$. Such epileptiform discharges are reported to be associated with cognitive impairment and-manifestation of ADHD symptoms ${ }^{25}$ and in such cases some have shown that antiepileptic use may abolish epileptiform discharges and even improve ADHD symptoms ${ }^{26}$.

EEG changes in ADHD group in our sample were generalized in all patients with abnormal EEG, this is in disagreement with Hughs and colleagues., (2000) who found that EEG recordings showed predominantly focal rather than generalized spike and wave complexes ${ }^{27}$. Also, Holtman and colleagues. (2003) reported that the frequency of centro-temporal (rolandic) spikes in children with ADHD was significantly higher than expected from normal children $^{28}$.

In the present study we excluded patients diagnosed ADHD who had history of seizures. However, Socanskia and colleagues., (2013) studied children with ADHD, found $2.3 \%$ had a history of epilepsy. The epilepsy diagnosis preceded the ADHD diagnosis, and was found in a significantly higher rate than would be expected in the general pediatric population. The majority of patients had mild epilepsy and ADHD-
Combined Inattentive/Hyperactive-Impulsive Subtype ${ }^{29}$. However, Davis and colleagues. (2010) reported that among ADHD patients, cases were 2.7 times more likely to have epilepsy than controls, had earlier seizure onset and a trend toward more frequent seizurs 5 .

In the current study, we did not divide the ADHD group statistically into; inattentive, hyperactive-impulsive and combined subtypes. Instead, we statistically studied the total score of ADHD and subscales of CPRS-R:L. There were no significant relation between gender of children in ADHD group and epileptic group in conner's subscales except in emotional-liability and inattention ( $p$ value 0.04 for each) Emotional lability and inattention were significantly more among males in ADHD group, which is in agreement with previous studies that did not find gender differences in impulsivity, academic performance, social functioning, fine motor skills, ADHD girls displayed greater intellectual impairment, lower levels of hyperactivity ${ }^{30}$. Further, we did not find any correlation between epilepsy patients' gender, type of seizures, age of onset of epilepsy, EEG abnormalities and their laterality with ADHD symptoms

In our study, there was significant differrence between epileptic children using AEDs and those not on AEDs in the total score of ADHD and subscales of CPRS$\mathrm{R}: \mathrm{L}$. This finding can be in line with Ying and colleagues., (2012) who concluded that the longer the period of antiepileptic medication, the higher the prevalence of the comorbidity of ADHD and that epileptic children receiving a combination of antiepileptic drugs had a higher prevalence of $\mathrm{ADHD}^{23}$. Many studies seem to suggest that the majority of AEDs have little effect on cognitive functioning, including attention 22,31

We could not find significant difference in known risk factors for both disorders which is in agreement with Silva and colleagues., (2013) who reported that contrary to other studies, new results from a populationbased, record linkage, case-control study 
show that low birth weight, post-term pregnancy, low Apgar scores, and fetal distress were not factors for ADHD irrespective of $\operatorname{sex}^{32}$.

\section{Conclusion}

The prevalence rate of ADHD in epileptic group of patients was $58.1 \%$. which means that children with epilepsy are at risk for ADHD. It is important to screen for inattention and other ADHD symptoms as part of standard care and management of epilepsy.

EEG study for cases of ADHD may be help in treating those patients. As, they have higher prevalence of EEG abnormalities than normal population. The higher the age of patients with ADHD the more the cognitive impairment and inattention.

Male with ADHD had more emotionalliability and inattention than females with ADHD.

\section{Limitations:}

The small sample size would not allow generalization of results.

\section{Recommendations:}

Extensive study should be done for childhood epilepsy to detect if ADHD symptoms precede the onset of epileptic seizures or the reverse.

EEG studying for ADHD patient might be mandatory and helpful for treatment plan of those patients.

\section{Abbreviations:}

- ADHD : Attention Deficit Hyperactivity Disorder.

- CPRS-R:L: Conners' Parent Rating Scales-Revised: Long.

- EEG: Electroencephalography.

- IQ: Intelligence quotient.

- GTCS: Generalised tonic clonic seizure

- AED: Anti-epileptic drug

\section{References}

1. Williams A E Giust J M, Kronenberger W G, Dunn D W.: Epilepsy and attention-deficit hyperactivity disorder: links, risks, and challenges Neuropsychiatr Dis Treat.2016; 12: 287-96
2. Russ SA, Larson K, Halfon N.: A national profile of childhood epilepsy and seizure disorder. Pediatrics.2012; 129(2):256-64

3. Soliman G, Afify M, Yehia M, AbdelNaem E, Abd Alkarim S: Attention Deficit Hyperactivity Disorder: an Epidemiological Study of Preschool and Primary School Children in Minia City. Elminia Med Bul.2010;21:171-9.

4. Polanczyk GV, Willcutt EG, Salum GA, Kieling C, Rohde LA.: ADHD prevalence estimates across three decades: an updated systematic review and meta-regression analysis. Int $\mathbf{J}$ Epidemiol. 2014; 43(2):434-42.

5. Davis SH M, Katusic S.K, Barbaresi W J, Killian, Weave J A, Ottman R, et al.,: Epilepsy in Children With ADHD: A Population-Based Study. Pediatr Neurol. 2010; 42: 325-30.

6. Cohen R, Senecky Y, Shuper A, Inbar D, Chodick G, Shalev V and Raz R: Prevalence of Epilepsy and AttentionDeficit Hyperactivity (ADHD) Disorder: A Population-Based Study.J Child Neurol 2013; 28(1): 120-3.

7. Dunn DW, Austin JK, Harezlak J. ADHD and epilepsy in childhood. Dev Med Child Neurol. 2003; 45:50-4.

8. Bennet-Back, O., Keren, A., \& Zelnik, N. Attention-deficit hyperactivity disorder in children with benign epilepsy. Pediatric Neurology.2011;44(3):18792.

9. Conners CK.: Conners' Rating Scales - Revised. Technical Manual. Toronto 2000: Multi-Health Systems.

10. Brikell I, Ghirardi L, D'Onofrio BM, Dunn DW, Almqvist C, Dalsgaard S, Kuja-Halkola R, Larsson H. Familial Liability to Epilepsy and AttentionDeficit/Hyperactivity Disorder: A Nationwide Cohort Study. Biol Psychiatry. 2018; 83: 173-80.

11. Salpekar J: Links Between Epilepsy and ADHD: Time to Focus and Act. Epilepsy Curr. 2018; 18( 3): 1601.Titlic M, Basic S, Hajnsek S, Lusic I. Comorbidity psychiatric disorders in epilepsy: A review of literature. Bratisl Lek Listy. 2009; 110:105-9.Weinberg WA, Harper CR, Schraufnagel CD. Attention deficit hyperactivity 
disorder: a disease or a symptom complex. J Pediatr.1997; 130:665-9.

14. Austin JK, Harezlak J, Dunn DW. Behaviour problems in children before first recognised seizure. Pediatrics. 2001; 107:115-22.

15. Kaufmann R, Goldberg-Stern H, Shuper A. Attention-deficit disorders and epilepsy in childhood: Incidence, causative relations and treatment possibilities. J Child Neurol. 2009; 24: 727-33.

16. Duran M. H. C., Guimarães C A., Montenegro M A, Neri M L. and Guerreiro M M:ADHD in idiopathic epilepsy Arq Neuropsiquiat 2014; 72(1):12-16

17. Choudhary A, Gulati S, Sagar R, Sankhyan N, \& Sripada K: Childhood epilepsy and ADHD comorbidity in an Indian tertiary medical center outpatient population. Scientific Reports. 2018; 8:2670.

18. Hesdorffer DC, Ludvigsson P, Olafsson E, Gudmundsson G, Kjartansson O, Hauser WA. ADHD as a risk factor for incident unprovoked seizures and epilepsy in children. Arch Gen Psychiatry. 2004;61:731-6.

19. Semrud-Clikeman $M$ and Wical B. Components of attention in children with complex partial seizures with and without ADHD. Epilepsia. 1999; 40: 211-15.

20. Piccirilli M, D'Alessandro P, Sciarma T. Attentional problems in epilepsy: possible significance of epileptogenic focus. Epilepsia .1994; 35:1091-6.

21. Zhang DQ, Li FH, Zhu XB, Sun RP. Clinical Observations on AttentionDeficit Hyperactivity Disorder (ADHD) in Children With Frontal Lobe Epilepsy. J Child Neurol. 2012; 29:54-7.

22. Williams J, Bates, S, Griebel ML. Does short-term antiepileptic drug treatment in children result in cognitive or behavioral changes. Epilepsia 1998; 39:1064-9.
23. Ying H., Jiong Qin, Jiang Yu-Wu, Jing C. Co-morbidity of attention deficit hyperactivity disorder in children with epilepsy chinese journal of contemporary paediatrics, 2012; 4: 89-92.

24. Richer LP, Shevell MI, Rosenblatt BR: Epileptiform abnormalities in children with attention deficit hyperactivity disorder. Pediatr Neurol.2002; 26:125-9

25. Castañeda-Cabrero C, Lorenzo-Sanz G, Caro-Martínez E, Galán-Sánchez JM, Sáez-Alvarez J, QuintanaAparicio P. Electroencephalographic alterations in children with attention deficit hyperactivity disorder. Rev Neurol. 2003; 37:904-8.

26. Laporte N, Sébire G, Gillerot Y, Guerrini R, Ghariani S. Cognitive epilepsy: ADHD related to focal EEG discharges. Pediatr Neurol. 2002; 27: 307-11.

27. Hughes JR, Deleo AJ, Melyn MA. The electroencephalogram in attention deficit-hyperactivity disorder: emphasis on epileptiform discharges. Epilepsy Behav. 2000; 1: 271-7.

28. Holtmann M, Becker K, KentnerFigura B. Increased frequency of rolandic spikes in ADHD children. Epilepsia.2003; 44:1241-4

29. Socanskia D, Aurlienb D, Herigstadc A, Thomsend $\mathrm{P} \mathrm{H}$, Larsene $\mathrm{T} \mathrm{K}$. Epilepsy in a large cohort of children diagnosed with attention deficit/ hyperactivity disorders (ADHD). Seizure. 2013; 22: 651-5

30. Gaub M, Carlson C. Gender Differences in ADHD: A Meta-Analysis and Critical Review. J Am Acad Child Adolesc Psychiatry 1997; 36:1036-45

31. Bourgeois BF. Antiepileptic drugs, learning and behavior in childhood epilepsy. Epilepsia.1998; 39: 913-21.

32. Silva D, Colvin L, Hagemann E, Bower C. Environmental Risk Factors by Gender Associated with AttentionDeficit/Hyperactivity Disorder. Pediatrics. 2013; 133:14-22. 